\title{
A MEDICALIZAÇÃO DA PEDAGOGIA: DISCURSOS MÉDICOS NA CONSTRUÇÃO DO DISCURSO PEDAGÓGICO E NOS MANUAIS DE FORMAÇÃO DE PROFESSORES EM PORTUGAL (SÉCULOS XIX-XX)
}

\author{
Antonio Carlos Correia ${ }^{1}$
}

\section{RESUMO}

O artigo reconstitui as modalidades através das quais o contributo dos médicos foi decisivo para a estruturação do discurso pedagógico que acompanhou a consolidação da Escola primária, em Portugal, entre os anos 1890 e 1930. Defendo que o discurso médico, através da reivindicação da sua cientificidade acerca da criança, naturalizou o modelo da escola graduada vigente, ocultando a sua natureza socialmente construída. Sem revelar o seu caráter localizado histórica e socialmente, a alteração do modelo da Escola atual está condenada ao insucesso porque não rompe com a racionalidade institucionalizada do ato pedagógico. Procuro abrir pistas para um posterior aprofundamento das possibilidades de reinvenção da organização da Escola, sustentadas por novos pressupostos científicos.

Palavras-chave: história da educação, discurso pedagógico, médicos, manuais pedagógicos para professores, resistência à mudança.

${ }^{1}$ Universidade de Lisboa (Ulisboa) Lisboa, Portugal. 


\section{LA MEDICALIZACIÓN DE LA PEDAGOGÍA: DISCURSOS MEDICOS EN LA FORMACIÓN DEL DISCURSO PEDAGÓGICO EN PORTUGAL E LOS LÍBROS DE TEXTO PARA MAESTROS EN PORTUGAL (SIGLOS XIX-XX)}

\section{RESÚMEN}

El artículo reconstituye las modalidades por que la contribución de los médicos fue decisiva para la estructuración del discurso pedagógico que ha acompañado la consolidación de la Escuela primaria, en Portugal, entre los años 1890 y 1930. Defiendo que el discurso médico, reclamando su cientificidad sobre el niño ha naturalizado el modelo de la escuela graduada vigente, ocultando su naturaleza socialmente construida. Sin revelar su carácter localizado histórica y socialmente, la alteración del modelo de la Escuela actual está condenada al fracaso porque no rompe con la racionalidad institucionalizada del acto pedagógico. Procuro abrir pistas para una posterior profundización de las posibilidades de reinvención de la Escuela, respaldadas por nuevos presupuestos científicos.

Palabras-clave: historia de la educación, discurso pedagógico, médicos, manuales de enseñanza para maestros, resistencia al cambio.

\section{MEDICALIZATION OF PEDAGOGY: MEDICAL DISCOURSES IN THE FORMATION OF THE PEDAGOGICAL DISCOURSE AND TEXTBOOKS OF TEACHERS TRAINING IN PORTUGAL (XIX-XX CENTURIES).}

\section{ABSTRACT}

The article reconstitutes the modalities through which doctor's contribution was crucial for the structuring of the pedagogical discourse throughout the consolidation process of the primary school in Portugal, between the years of 1890 and 1930. I therefore argue that medical discourse assuming its scientific character about the child naturalized the current graded school model therefore hiding his socially constructed nature. I'm seeking out new avenues to be later deepened about the possibility of the reinvention of the School under new scientific foundations. Keywords: history of education, pedagogical discourse, physicians, teachers training pedagogical books, resistance to change.

\section{MÉDICALISATION DE LA PÉDAGOGIE: DISCOURS MÉDICALES DANS LA FORMATION DU DISCOURS PÉDAGOGIQUE ET LES MANUELS POUR LA FORMATION DES ENSEIGNANTS AU PORTUGAL (SIÈCLES XIX-XX)}

RESUMÉ 
L'article retrace les modalités a travers lesquelles l'apport des médecins a été crucial pour la structuration du discours pédagogique accompagnant le procès de consolidation de l'écola primaire au Portugal, entre les années 1890 et 1930 . Je soutiens que le discours medical en invoquant sa scientificité a propos de l'enfant a contribué à la réification du modèle d'école graduée en occultant sa nature socialement construite. Je cherche de nouvelles voies de recherche à approfondir dans l'avenir sur la possibilité de réinventer l'École d'après nouveaux fondements scientifiques.

Mots-clés: histoire de l'éducation; discours pédagogique, médecins, manuels pédagogiques pour enseignants; résistance au changement. 


\section{INTRODUÇÃO: PARA UM ENTENDIMENTO MAIS AMPLO DA INTERVENÇÃO DOS MÉDICOS NA CONSTRUÇÃO DO DISCURSO PEDAGÓGICO}

Neste artigo, procuro contribuir para o entendimento das razões profundas que sustentam a dificuldade atual da Escola primária ou básica, em Portugal, em encontrar novos modelos organizacionais e em redefinir os modos de pensar o aluno, a aprendizagem e o papel do professor. Como me proponho fazê-lo? Colocando como hipótese de trabalho que a Pedagogia desenvolveu historicamente um paradoxo conceptual ao colocar a criança individual no centro de toda a racionalidade do ato pedagógico, pois os processos e organização das aprendizagens são, no contexto escolar, eminentemente resultantes de interações coletivas. Ao validar um modelo de organização escolar específico, o da escola graduada, no pressuposto que corresponderia ao desenvolvimento natural da criança e das necessidades da sua aprendizagem, colocou toda a ênfase na construção da homogeneidade coletiva, assente na reunião de indivíduos agrupados pelas suas características semelhantes. Esse processo decorreu na viragem do século XIX para o $\mathrm{XX}$, no contexto da edificação do Estado-Nação.

A validação da pedagogia escolar foi alcançada através da intervenção dos médicos, dos seus saberes e da sua intervenção na Escola e na formação de professores. Enquanto grupo profissional emergente, precisava demonstrar a sua imprescindibilidade e eficácia na resolução de processos sociais críticos para a regeneração da sociedade, nos quais as medidas de universalização da escolaridade elementar para as crianças oriundas dos meios pobres e trabalhadores constituiam uma peça essencial.

A partir dos pressupostos antes enunciados, este artigo pretende constituir um ensaio, uma reflexão, a partir da identificação das modalidades através das quais o discurso médico, em Portugal, se incorporou ao discurso pedagógico, em particular, no ensino primário. Nas dificuldades de organização das interações educativas e no fracasso escolar das crianças oriundas das 
camadas populares, foram ocultadas as razões de natureza social e cultural e, em seu lugar, para explicar essas dificuldades, ganharam centralidade a natureza individual da aprendizagem de cada criança.

A chave para responder às transformações atuais da sociedade e do público escolar passaria pela explicitação da natureza e das consequências da intervenção dos médicos na naturalização do modelo organizacional da escola graduada. Requer também uma abordagem da criança, não apenas individual, mas igualmente orientada para a concetualização dos processos de aprendizagem numa lógica coletiva, de grupo, cuja essência é cada vez mais a diversidade.

O período tratado é o que decorre entre os anos 1890 e o início dos anos 1930. A escolha deste arco cronológico justifica-se por ser neste contexto temporal que, em Portugal, se afirma institucionalmente a presença da Pedagogia Experimental, no quadro da emergência das Ciências da Educação, com particular expressão na formação de professores no Ensino Normal Primário (NÓVOA, 1998). Foi também nestes anos que se desenvolveu a institucionalização da Medicina enquanto profissão, à semelhança do que vinha a acontecer na Europa ocidental e nos Estados Unidos (VELOSO, 2017a).

Para estabelecer o referencial teórico, utilizo a conceptualização de Basil Bernstein sobre o processo constitutivo do discurso pedagógico. Bernstein definiu o discurso pedagógico enquanto gramática de recontextualização que procede à apropriação e recombinação de discursos produzidos em outros contextos, transformando-os num discurso novo, diferente, cujas regras de composição interna são precisamente ditadas pela forma como são equacionados os saberes no contexto escolar (BERNSTEIN, 1986, p. 214).

Procedi a uma revisão de fontes e de bibliografia utilizadas noutros contextos de pesquisa, nomeadamente, imprensa pedagógica e de ensino, legislação e manuais pedagógicos para formação de professores, atendendo agora à temática em análise. Para conferir uma perspectiva de conjunto, comecei por socorrer-me de dois instrumentos essenciais: refiro-me à imprensa 
de educação e ensino: repertório analítico (séculos XIX-XX), publicado, em Lisboa, em 1993, e ao Dicionário de Educadores Portugueses, dado à estampa em 2003, no Porto. Ambas as obras são de autoria coletiva e realizadas sob a direção de António Nóvoa.

Em segundo lugar, recorri a publicações de diversos autores, cujas abordagens, direta ou indiretamente, contemplam elementos relevantes de informação e de reflexão sobre a presença dos médicos e do discurso médico no pensamento pedagógico, nas instituições de ensino primário em Portugal, no período considerado (CORREIA, 2019; CORREIA; SILVA, 2002; CORREIA; PERES, 2005; FERREIRA, 2003; 2014). Em terceiro lugar, utilizei alguns autores e obras que abordam a emergência da medicina social e as transformações da profissão médica na Modernidade (FOUCAULT, 2002; PINELL, 1995; PORTER; PORTER, 1988). Finalmente, em quarto lugar, analisei um conjunto de manuais pedagógicos para formação de professores, decorrentes das lições professadas na Escola Normal Primária de Lisboa, no período considerado, elaborados por professores normalistas médicos ou que mantiveram colaboração muito estreita com médicos (FERREIRA, 1921; LIMA, 1927, 1929, 1932, 1936; PIMENTEL FILHO, 1916, 1919, 1929, 1934, 1935a, 1935b; VASCONCELOS, 1909, 1923). No corpus tratado, estão incluídas $1^{a^{a}}$ e $2^{\mathrm{a}}$ S edições dos mesmos manuais pedagógicos, uma vez que tratam de versões profundamente reformuladas e diferentes entre si.

As entradas referidas garantem que o estudo das implicações da intervenção dos médicos na construção discursiva da Pedagogia não se limita ao registo do peso quantitativo e estritamente descritivo dos médicos envolvidos. $\mathrm{O}$ contributo médico determinou uma representação social da criança escolar e dos processos de aprendizagem que ainda hoje se mantém nos fundamentos da organização do trabalho escolar (docente e discente) que dificulta ou mesmo impede transformações estruturais. Denise Jodelet explica com muita clareza o potencial explicativo e o conteúdo epistemológico do conceito de representação social quando, no quadro das ciências sociais, relaciona o saber assim produzido 
com a ação:

As representações sociais constituem fenómenos sociais complexos sempre ativados e atuantes sobre a vida social. Na sua riqueza fenomenológica assinalam-se elementos diversos dos quais alguns são por vezes estudados de modo isolado: elementos informativos, cognitivos, ideológicos, normativos, crenças, valores, atitudes, opiniões, imagens, etc. Mas estes elementos subjazem sempre a um saber que diz qualquer coisa sobre o estado da realidade. E é esta totalidade significante que, em relação com a ação, se situa no centro da pesquisa científica. (JODELET, 2003, p. 52-53 - tradução minha). ${ }^{2}$

Serge Moscovici evidencia as três fases pelas quais as representações se formam e intervêm no estabelecimento do senso comum disseminado na sociedade:

a) a fase científica de sua elaboração, a partir de uma teoria, por uma disciplina científica (economia, biologia, etc.); b) a fase "representativa", em que ela se difunde dentro de uma sociedade e suas imagens, conceitos e vocabulário são difundidos e adaptados; c) $a$ fase ideológica, em que a representação é apropriada por um partido, uma escola de pensamento ou um órgão do estado e é logicamente reconstruída, de tal modo que um produto, criado pela sociedade como um todo, pode se legitimar em nome da ciência. (MOSCOVICI, 2004, p. 96).

Trata-se de uma formulação absolutamente essencial para se perceber como as representações sociais em torno da criança, da escola e do processo pedagógico se difundiram na sociedade e converteram em postulados do senso comum associados a um estatuto científico. 3

2" ...les représentations sociales sont des phénomènes complexes toujours activés et agissant sur la vie sociale. Dans leur richesse phénoménale on repère des éléments divers dont certains sont parfois étudiés de manière isolée : éléments informatifs, cognitifs, idéologiques, normatifs, croyances, valeurs, attitudes, opinions, images, etc. Mais ces éléments sont toujours sous l'espèce d'un savoir disant quelque chose sur l'état de la réalité. Et c'est cette totalité signifiante qui, en rapport avec l'action, se trouve au centre de l'investigation scientifique“.

3 S. Moscovici desenvolveu a sua abordagem deste processo estudando a difusão da psicanálise em França (MOSCOVICI, 2004, p.95). 


\section{PROPOSTA DAS TRAVES-MESTRAS DE UMA RECONCEPTUALIZAÇÃO: REGRESSANDO A BERNSTEIN PARA DESMONTAR O TEXTO PEDAGÓGICO}

O sociólogo Basil Bernstein identificou, nos seus trabalhos, a existência de três contextos estruturantes na elaboração do discurso pedagógico: o da produção ou contextualização primária; o contexto secundário ou campo da reprodução e, finalmente, um terceiro, o dos campos de recontextualização (BERNSTEIN, 1990, p. 191-192). O processo constitutivo do texto e, genericamente, do discurso pedagógico estão bem claros na citação seguinte do autor. Embora longa, justificar-se-á essa extensão na medida em que nos coloca perante a complexidade dos processos inerentes à construção do discurso pedagógico:

Quando um texto é apropriado por agentes de recontextualização, ocupando posições neste campo, o texto sofre habitualmente uma transformação anterior à sua relocalização. $O$ formato desta transformação é regulado por um princípio de descontextualização. Este processo refere-se à mudança sofrida pelo texto na medida em que é deslocado e recolocado. Este processo garante que o texto não é mais o mesmo texto: 1- o texto mudou a sua posição relativamente a outros textos, práticas e posição. 2 - Em si mesmo, o texto foi modificado através da seleção, simplificação, condensação e elaboração. 3 - O texto foi reposicionado e refocalizado. O princípio de recontextualização regula o novo posicionamento ideológico do texto no seu processo de recolocação em um ou mais níveis do campo de reprodução. Uma vez nesse campo, o texto sofre nova transformação ou reposicionamento uma vez que se torna ativo no processo pedagógico em cada nível. É crucial distinguir, e analisar, as relações entre, pelo menos, as duas transformações do texto. A primeira, é a transformação do texto no interior do campo de recontextualização e, a segunda, é a transformação do texto transformado no processo pedagógico, à medida que é ativado no processo de reprodução dos que dele se apropriaram. É o campo de recontextualização que gera as posições da teoria, da pesquisa e da prática pedagógicas 
(BERNSTEIN, 1990, p. 192-193 - tradução minha)4.

Muitos enunciados, quer os oriundos diretamente do discurso médico, quer aqueles produzidos no âmbito da Pedagogia Experimental e das Ciências da Educação, decorrem, por vezes, de recontextualizações geradas pela circulação de pessoas e ideias, oriundas do movimento pedagógico internacional, em particular europeu (França, Bélgica e Suíça) mas também, de forma crescente, dos Estados Unidos.

Trata-se, portanto, de tomar como ponto de partida a ideia que a Pedagogia Moderna se formou enquanto um discurso híbrido que naturalizou e legitimou socialmente os modos de organização pedagógica. Através da prática clínica bem como através da produção de saber médico veiculado na imprensa, nos eventos internacionais e na formação de professores, essas produções foram mobilizadas em função de interesses políticos, sociais e científicos díspares, mas, para os quais, os enunciados produzidos foram instrumentais no quadro do processo de reconhecimento e legitimação, enquanto grupo profissional, assim como na validação do modelo escolar.

A participação dos médicos na esfera educativa escolar foi uma de inúmeras frentes sociais onde, enquanto classe profissional, afirmaram o poder social do conhecimento científico e da prática clínica. A medicina interveio nos desígnios reformadores através da Higiene Social e da Medicina Social na

4 O texto original é: "When a text is appropriated by recontextualizing agents, operating in positions of this field, the text usually undergoes a transformation prior to its relocation. The form of this transformation is regulated by a principle of decontextualizing. This process refers to the change in the text as it is first dislocated and relocated. This process ensures that the text is no longer the same text: 1 the text has changed its position in relation to other texts, practices, and position. 2 The text itself has been modified by selection, simplification, condensation, and elaboration. 3 The text has been repositioned and refocused. The decontextualizing principle regulates the new ideological positioning of the text in its process of relocation in one or more of the levels of the field of reproduction. Once in that field, the text undergoes a further transformation or repositioning as it becomes active in the pedagogic process within a level. It is crucial to distinguish between, and analyse, the relations between the two transformations, at least, of a text. The first is the transformation of the text within the recontextualizing field, and the second is the transformation of the transformed text in the pedagogic process as it becomes active in the process of the reproduction of acquirers. It is the recontextualizing field which generates the positions of pedagogic theory, research, and practice" (BERNSTEIN, 1990, p. 192-193). 
Europa, nomeadamente, em Inglaterra França ou Alemanha (FOUCAULT, 2002); PINELL, 2011; PORTER; PORTER, 1988). A presença dos médicos na definição e implementação dessas políticas ocorreu em diversos domínios de intervenção, em particular nos meios urbanos, desde a habitação popular, o funcionamento dos hospitais, a vacinação, a luta contra a tuberculose e também na escolaridade básica, desde os edifícios às atividades escolares, desenrolandose seja sob a égide do Estado, ou outras dinâmicas sociais (FOUCAULT, 2002, p. 134-156; VELOSO, 2017a).

O poder social dos médicos na esfera educativa escolar pode ser abordado em termos demográficos, pelo número de representantes da profissão médica com intervenção em algum domínio do universo escolar; no plano institucional, pelos cargos e funções que desempenharam em instituições educativas, entidades governamentais com jurisdição escolar, incluindo a participação na definição das políticas públicas da educação; no plano científico, através da realização de estudos experimentais realizados em torno da criança, das aprendizagens realizadas em contexto escolar, das dificuldades, problemas e patologias diagnosticados no âmbito das atividades escolares; no plano da construção de uma opinião pública, através da publicação de artigos de opinião na imprensa de grande circulação, em revistas especializadas, seja de Medicina ou de Pedagogia; e na afirmação do status profissional, através da participação em associações e sociedades científicas, profissionais ou outras.

No momento histórico da institucionalização da escolaridade primária, universal e obrigatória, em Portugal, mobilizando as crianças dos meios populares rurais e urbanos, os médicos protagonizaram uma intervenção determinante na definição e legitimação dos métodos pedagógicos, na representação do processo de aprendizagem e na naturalização das desigualdades sociais presentes nas dificuldades escolares das crianças oriundas dos meios populares (VARELA, 1992; VARELA E ALVAREZ-URIA, 1991). A participação dos médicos no discurso pedagógico fez-se, não só através da invocação da sua autoridade específica clínica e/ou científica, como também 
através da sua colaboração direta, nomeadamente, no Ensino Normal, na elaboração de manuais para a formação dos futuros professores e na produção pedagógica.

O movimento da Escola Nova representou uma das tentativas mais esforçadas na elaboração e introdução do que Julia Varela classificou de pedagogias corretivas (VARELA, 1992). As pedagogias corretivas sucederam-se, segundo a autora, às pedagogias disciplinares, elaboradas a partir do século XVIII, e encontram os seus fundamentos experimentais e conceptuais no campo da infância anormal. A aplicação do modelo pedagógico centrado na individualidade da criança, e respectivas implicações na estrutura e caráter das atividades escolares, baseou-se na convicção de que era possível realizar a "socialização universal, individualizada, válida para qualquer sujeito, desligada já das classes sociais e do contexto histórico e legitimada por códigos chamados experimentais" uma vez que a criança natural surgia da negação dos conflitos sociais e da luta pela hegemonia social (VARELA, 1992, p. 20).

Nessa demanda, acabou por ser fabricada uma legitimação conceptual para a distinção e separação entre os normais e os anormais. A globalização da educação escolar operou a sobreposição da condição de criança à de escolar. A descoberta da natureza específica da criança, acompanhada de propostas de periodização do seu desenvolvimento natural traduziu-se por uma azáfama de medições, de observações e de quantificação nos planos biológico, fisiológico, psicológico e mental. Esse imenso campo de observações empíricas e dados experimentais, inspirado no trabalho desenvolvido com os anormais em instituições específicas, produziu o conceito de normalidade escolar, que rapidamente se impôs como bitola da normalidade, ou seja, as normas escolares transmutaram-se em normas naturais do desenvolvimento humano nas suas etapas da infância e juventude (PINELL, 1995, p. 32).

Em Portugal, a introdução de novos paradigmas da profissão médica assim como do seu papel social encontra raízes nas Escolas Médico-Cirúrgicas do Porto e de Lisboa, que surgiram da reforma das escolas cirúrgicas, criadas 
em 1825. Acompanhou, de resto, embora com algum desfasamento temporal, o que estava a acontecer na Europa. A reforma das Escolas Médico-Cirúrgicas assentou-se na ruptura com o modelo tradicional do ensino médico da Universidade de Coimbra e com o paradigma até aí imperante da prática clínica. As Escolas Médico-Cirúrgicas tiveram um papel crucial na circulação e atualização das ideias científicas e das práticas médicas no estrangeiro, em especial na Inglaterra, França e na Alemanha, contribuindo para a formação de uma nova geração de médicos imbuídos dos princípios da Higiene e da Medicina Social (DORIA, 2017).

A medicina, à semelhança de outras áreas científicas, passava por transformações profundas, nos métodos, nas concepções, nos objetos, na organização profissional e acadêmica. $\mathrm{O}$ surgimento de novas especialidades, o desenvolvimento das vertentes científica e experimental, nomeadamente, na Fisiologia e, ao nível dos processos psíquicos, na Psiquiatria, tornaram a Escola um imenso campo de observação e de afirmação da pertinência social das novas disciplinas médicas (VELOSO, 2017b, p. 439-459). Analisando as dissertações apresentadas pelos alunos da Escola Médico-Cirúrgica do Porto, entre 1837 até ao início do século XX, António Gomes Ferreira sublinha o crescimento das temáticas abordadas na esfera educativa. Nelas, defendia-se a intervenção médica, tanto nos casos particulares - a dimensão clínica - como também se reclamava a legitimidade e a primazia na definição dos fundamentos conceptuais e metodológicos em que o ensino deveria assentar. (FERREIRA, 2003, p.20).

Eventos como o XV Congresso Internacional de Medicina em Lisboa, em 1906, promovido e realizado por Miguel Bombarda, tal como a criação das Universidades de Lisboa e do Porto (decreto de 24 de março de 1911), simbolizam as transformações em curso no seu protagonismo social e na sua inserção nas novas tendências da comunidade científica internacional. A nova geração profissional de médicos estabeleceu redes e múltiplos campos de intervenção social, cultural e política. Os médicos participaram na 
movimentação das elites sociais e culturais, em busca de um modelo educativo escolar que consubstanciasse um projeto social suscetível de colocar a sociedade portuguesa ao nível das principais metrópoles europeias.

Nessa estratégia de afirmação social, é visível o protagonismo de numerosos médicos na cultura e na militância cívica e política. É o caso da participação de figuras da medicina na fundação da Revista Pela Grei, em 1918, na fundação da Seara Nova, em 1921 e da Revista Lusitânia, fundada em 1924. Neste movimento, surgem, a par de outras figuras relevantes da Pedagogia em Portugal, Agostinho de Campos (diretor-geral da Instrução Pública entre 1906 e 1910), António Arroyo (inspetor do Ensino Elementar Industrial e Comercial entre 1890 e 1926 e sócio fundador da Liga Nacional de Instrução, em 1908), António Sérgio ou Faria de Vasconcelos, os médicos Ricardo Jorge, Celestino da Costa (sócio e fundador da Liga de Educação Nacional, em 1908, sócio da Sociedade de Estudos Pedagógicos, a partir de 1918) (COSTA, 1985, p. 6-7). Como diz Maria Rita Garnel, "se houve grupo socioprofissional que conseguiu, ao longo de Oitocentos, de forma consistente e continuada, impor o seu saber como princípio de conhecimento, de orientação e de transformação da sociedade, esse grupo foi o dos médicos (GARNEL, 2003, p. 214).

Ao consultar a lista de sócios efetivos da Sociedade de Estudos Pedagógicos (fundada em 1910), verifica-se que o peso dos sócios médicos ou com formação em Medicina, no final de 1910, era de cerca de 16\% e, em 1921, tinha subido para 20\%, de acordo com as listas publicadas na Revista de Educação Geral e Técnica (Boletim da Sociedade de Estudos Pedagógicos) (vol. I, p. 84-87, janeiro de 1911; Série VII, n. ${ }^{\circ \text { s }} 3$ e 4, p. 127-134, julho de 1921).

Alguns dos representantes da profissão médica foram protagonistas na definição das políticas públicas e na construção do discurso pedagógico. A sua importância resultou dos múltiplos cargos públicos que ocuparam, educativos e políticos. Médicos como Costa Sacadura, António Aurélio da Costa Ferreira, Alberto Pimentel Filho ou Ladislau Piçarra, além de sócios da Sociedade de Estudos Pedagógicos, intervieram na formação de professores, nos serviços de 
sanidade escolar, em congressos e eventos nacionais e internacionais, bem como na imprensa pedagógica e de ensino.

Nas primeiras décadas do século $\mathrm{XX}$, assim como já o tinha sido nos finais da $2^{\mathrm{a}}$ metade do século XIX, a orientação principal das políticas sociais foi a de regenerar a sociedade, em particular as classes trabalhadoras, entendidas como fonte maior dos perigos e riscos que ameaçavam a vida urbana e dos males sociais. Costa Sacadura exemplificava, no Portugal de 1911, essa preocupação, tendo como cenário de fundo o ensino primário:

É com efeito preciso ter estado, como eu, em contacto durante anos com as creanças que frequentam as nossas escolas primárias e secundárias, para fazer uma ideia clara do estado de miséria fisiológica em que se encontram, e poder avaliar o perigo que nos ameaça se não pensarmos a sério na maneira de o conjurar. Tudo quanto se faça para entravar a marcha desse vírus que roe pouco a pouco a mentalidade, a energia e o caracter da creança portugueza, merece o aplauso veemente e o auxílio inconcusso de todos os que amam sinceramente a sua pátria (SACADURA, 1911, p. 4-5).

As palavras de Costa Sacadura exemplificam a agenda social da época, em que se apontavam os riscos de definhamento físico e moral dos Portugueses e, em especial, das crianças dos meios urbanos mais pobres. São também programáticas, pois, já estando presentes no seu percurso enquanto médico escolar e inspetor sanitário escolar orientarão, alguns anos mais tarde, a partir de 1918, a sua atividade como professor na Escola Normal Primária de Lisboa, onde lecionou Higiene Geral, Higiene Escolar e Pedologia (CORREIA, 2003). Conjuntamente com outros médicos, intervindo no ensino normal primário, irá contribuir para a formação dos professores, incorporando as preocupações sociais e os contributos científicos da época no conteúdo das suas lições e dos textos pedagógicos. 


\section{A FORMAÇÃO NAS ESCOLAS NORMAIS COMO ETAPA OBRIGATÓRIA NA PROFISSIONALIZAÇÃO DOS PROFESSORES. OS MÉDICOS-PEDAGOGOS E MANUAIS PEDAGÓGICOS.}

O período determinante para a consolidação do modelo organizacional da escola graduada, no ensino primário, em Portugal, situa-se entre as Reformas do Ensino Primário de1894-1896 e de 1901-1902, respectivamente. A partir da Reforma de 1901, o acesso à profissão docente, no ensino primário, passa a fazer-se, obrigatoriamente, através do curso das Escolas Normais Primárias. Para António Nóvoa, trata-se de um acontecimento capital no processo de profissionalização dos professores (NÓVOA, 1987, p. 652). A implantação da República, em 5 de outubro de 1910, veio dar um impulso ideológico e organizativo fundamental para que a frequência do ensino primário pela generalidade das crianças oriundas das classes trabalhadoras constituísse uma preocupação política prioritária.

A prioridade política atribuída à educação do povo e à formação de cidadãos através do ensino primário traduziu-se na preocupação com a qualidade da formação pedagógica e profissional dos professores primários nas Escolas Normais. Os efeitos práticos das medidas tomadas estenderam-se até ao início dos anos 1930, quando o Estado Novo, de Salazar, para quebrar a influência do ideário pedagógico republicano nos professores e alunos das Escolas Normais, as encerra em 1936, só as reabrindo cinco anos depois, já com um formato completamente alterado.

A consagração da autoridade médica sobre a escolaridade revela-se também em pormenores da lei. No decreto ${ }^{0}{ }_{4}^{4}$, de 19 de setembro de 1902, que regulamentou a reforma da Instrução Primária, em Portugal, promulgada em 24 de dezembro de 1901, o legislador declara que estariam isentas da frequência escolar as crianças que "por atestado médico demonstrarem incapacidade para a frequência escolar" (art. $5^{\circ}$ - sublinhados meus). 
É a primeira vez que a lei declara que a incapacidade de frequência escolar por parte de alguma criança é matéria do foro médico. As condições relativas ao cumprimento da obrigatoriedade escolar, o recenseamento, a matrícula e a frequência, assim como a validação do seu incumprimento por atestado médico seriam reiteradas quer no Regulamento do ensino primário, publicado em 26 de julho de 1911, ou no Regulamento, de 29 de setembro de 1919.

No quadro da nova organização dos serviços da Direção Geral de Instrução Pública, (Reforma do Ensino Primário, em 1901), foi criada a Inspeção Sanitária Escolar. No relatório que precedia o referido decreto, salientava-se que "a inspeção sanitária escolar é uma consequência lógica da instrução obrigatória". Dizia-se também que a mais alta competência administrativa, a experiência dos inspectores pedagógicos, e o mais desvelado cuidado pelos interesses da infância não podem substituir os conhecimentos exactos da ciência, as indicações rigorosas da fisiologia e da higiene (Decreto $\mathrm{n}^{0}$ 2, de 24 de dezembro de 1902).

O médico higienista das escolas entrava no quotidiano escolar, não enquanto entidade exterior à escola, mas para passar a fazer parte desse quotidiano. A sua função era a de

\begin{abstract}
fazer ouvir os seus conselhos, o discutir, no ponto de vista da sua competência especial, os sistemas modernos e os antigos que deseja substituir, as horas de trabalho e de repouso, o agrupamento das disciplinas nos programas, a escolha do material de ensino, o tipo de impressão dos livros, quadros parietais, mapas, tudo quanto se refere a instalações escolares: cubagem, ventilação, iluminação natural ou artificial, modelos e disposição das mesas e das bancadas, a profilaxia das doenças escolares, etc. (Decreto $\mathrm{n}^{0} 2$, de 24 de dezembro de 1902).
\end{abstract}

Esta novidade é ainda mais relevante pois

pelo que respeita à instrução primária até 1901, a inspecção sanitária escolar competia aos delegados e subdelegados de saúde, isto é, não havia lei especial que a regulasse, sendo, portanto, consideradas as 
escolas como habitações colectivas e sujeitas às leis gerais sanitárias (PIMENTEL FILHO, 1919, p. 191).

As atividades escolares foram sendo concebidas na perspectiva de um isolamento social e espacial cada vez mais sustentado por argumentos médicohigiénicos. Esses argumentos ganharam particular destaque a partir das duas derradeiras décadas do século XIX. A remodelação do calendário escolar surgiu como uma das novas bandeiras da racionalidade pedagógica e, nesse contexto, a problemática respeitante ao período das férias grandes ganhou uma relevância particular. Na busca dos métodos de ensino mais eficazes, procurou-se determinar a duração dos períodos de atenção de que eram capazes as crianças nas diversas idades escolares.

O alargamento da população escolar a cada vez mais vastas camadas da população trabalhadora, rural e urbana, proporcionado pelas medidas de combate ao analfabetismo e de efetivação da obrigatoriedade do ensino primário elementar, colocou, com premência, a questão de lidar com a heterogeneidade e a inadaptação ao meio escolar dos alunos. A ação das instituições vocacionadas para o tratamento e educação das crianças anormais, ganhou uma centralidade social que levou a transpor o campo de aplicação dos materiais, técnicas e conceitos ensaiados no contexto das crianças deficientes à educação escolar em geral (WAGNON, 2013).

Dentre aquele tipo de instituições, pela sua dimensão e centralidade, destacou-se a Casa Pia de Lisboa, fundada em 1780. Destinava-se, inicialmente, a recolher crianças e jovens órfãos ou abandonados, assim como vagabundos e prostitutas. Com a queda do regime monárquico e a implantação da República, em 5 de outubro de 1910, a Casa Pia adquiriu um novo protagonismo na produção e ensaio de modelos pedagógicos destinados às classes populares e aos deficientes, particularmente com a criação do Instituto Médico-Pedagógico, em 1911.

A educação escolar dos deficientes mentais, visuais e auditivos e as 
instituições onde era realizada constituíam matéria dos manuais de Pedagogia e de História da Educação, dirigidos aos alunos das Escolas Normais Primárias. Do mesmo modo, a propósito do desenvolvimento da Pedotecnia Judiciária, em Portugal, eram apresentados os casos de diversas casas de detenção e correção, escolas agrícolas, a criação dos Tribunais Infantis e das Tutorias ou da Comissão de Proteção a Menores de Lisboa (em 1911), em que um dos membros além do médico António Cassiano Neves, era o pedagogo Adolfo Lima (PIMENTEL FILHO, 1919, p. 261).

A escola converteu-se, implicitamente, no padrão pelo qual passaram a ser aferidas as leis do desenvolvimento natural da criança.

\footnotetext{
Dos estudos psicopedológicos ressalta, como problema principal, a classificação dos «tipos mentais» que as crianças apresentam e o importantíssimo princípio de que a criança não é fisiológica, nem psicologicamente um adulto, ainda que em miniatura, mas um tipo social em constante evolução. É sobre este princípio essencial que deve fazer-se a classificação dos tipos de crianças, bifurcando-a, inicialmente, em dois grupos: crianças normais e crianças anormais, e estas, por sua vez, em super-anormais e sub ou infra-anormais (LIMA, 1936, p. 61).
}

A racionalização da Escola, enquanto meio higiénico corretor dos desequilíbrios e taras sociais, caraterísticos nas crianças oriundas dos meios populares, desempenhou um papel decisivo na representação da regeneração da sociedade. A implantação de um conjunto de medidas sociais, como a criação de abrigos e asilos para as crianças e jovens delinquentes, mães solteiras, creches e outros, a par do estabelecimento de uma matriz escolar obedeceu a preocupação de que "cada geração é um produto dos três fatores: hereditariedade, ambiência e educação" (LIMA, 1936, p. 88).

A intervenção médica, para a qual já chamei a atenção previamente, evoluiu de uma intervenção exterior à Escola, nos termos do que Faria de Vasconcelos apelidou de medicina repressiva "de profilaxia das doenças contagiosas”, para uma situação em que passava a participar da construção social 
do discurso sobre a Escola e estendia o âmbito da sua ação à racionalização do ato pedagógico. Tratava-se de afirmar a medicina preventiva:

que dava ao médico intervenção mais constante e eficaz: o exame do desenvolvimento físico da criança. $\mathrm{E}$ assim, o primeiro passo estava dado para que dentro em pouco a medicina escolar adquirisse a altíssima importância que hoje se lhe assina. Quando pelo exame do desenvolvimento físico se viu que o seu atraso, fraqueza ou defeituosidade era um obstáculo ao desenvolvimento intelectual e moral da criança, então compreendeu-se que a higiene mental era tão importante como a física. A famosa questão da surmenage tratada pela medicina escolar, assim como a questão dos atrasados mentais, dos anormais profundos, deu à colaboração médico-pedagógica um valor incontestável. Foi sobretudo nas escolas especiais de anormais onde primeiro se realizou esta cooperação eficaz do médico e do pedagogista, tornando-se um facto definitivamente admitido. A intervenção do médico na escola é absolutamente indispensável não só do ponto de vista higiénico, profiláctico, mas também do ponto de vista educativo (VASCONCELOS, 1923, p. 9-10).

Foi deste modo que o saber médico impregnou intensamente a construção de categorias estruturantes da cultura pedagógica. Tópicos abarcando a fadiga escolar, a adequação dos horários das atividades e das férias escolares, a representação do aluno normal situada no aluno médio, a importância dos testes mentais e a definição da correspondência ou discrepância da idade cronológica com a idade mental, com o consequente estabelecimento de tipologias de anormalidade, difundiram-se amplamente, sempre com a chancela da autoridade médica. Este movimento discursivo e institucional incluiu a Psicologia, a Pedagogia Experimental, a Pedologia. Alberto Pimentel Filho, ao caracterizar o movimento psicopedológico em diversos países, chamava a atenção para o facto de que

o estudo da Psicologia infantil não partiu das escolas, onde aliás existem os elementos indispensáveis para a sua elaboração. Foram criaturas estranhas ao ensino, filósofos, médicos, psicólogos, que nunca ou apenas incidentalmente exerceram a profissão de educadores, que proclamaram o estudo da criança como a própria 
condição das tentativas pedagógicas (PIMENTEL FILHO, 1919, p. 147).

O diretor da Casa Pia, António Aurélio da Costa Ferreira, figura proeminente no domínio do ensino e da Pedagogia de alunos com deficiências incentivou a introdução dos novos métodos e conceitos da psicologia e pedagogia experimentais, tomando ele próprio parte ativa nesse processo. A nova racionalidade pedagógica orientava-se no sentido da construção e aperfeiçoamento de uma tecnologia educativa que ia beber ao paradigma emergente da organização científica do trabalho.

A. A. da Costa Ferreira defendia que o papel da Pedagogia era o de "fazer do anormal, tanto ou aproximadamente tanto como se faz do normal, um indivíduo que se assista a si próprio e favoreça, pouco ou muito, a coletividade" o que implicava, igualmente, que

não pode consentir a pedagogia a mistura de normais com anormais, pelo prejuízo que dela resultaria para os dois lados. A selecção é exigida, deixando-se os normais com os processos ordinários e os anormais com os processos especiais, sem prejuízo da reciprocidade quando e nos casos aconselhados (FERREIRA, 1914, p. 181-187).

Adolfo Lima dá-nos conta da mudança na perspectiva orientadora da Pedagogia, quanto à ordenação mais adequada das disciplinas para a aprendizagem das crianças. Diz este autor que, ao contrário da representação tradicional que situava a criança como destinatário da transmissão de saberes, a Didática, capítulo da Pedagogia Moderna, científica e experimental, ordenava cientificamente os conteúdos e as práticas educativas para o desenvolvimento global da criança (LIMA, 1927, p. 271-272).

\section{REFORMAS, CONGRESSOS, ASSOCIAÇÕES, SOCIEDADES E IMPRENSA}


Os momentos de Reformas Educativas constituem momentos privilegiados para a circulação de ideias e o estabelecimento de plataformas de entendimento entre grupos de interesses de diferentes setores da sociedade. No caso da Instrução Primária e do protagonismo da profissão médica, considero que há três datas podem ser consideradas como momentos-âncora nesse processo. Refiro-me ao Projeto de Reforma de 1918, à Reforma de 1919 e ao Projeto de Reforma de 1923, que também ficou conhecida como Reforma Camoesas.

O Projeto de Reforma de 1918 é relevante para evidenciar o percurso das iniciativas que conduzirão, um pouco mais tarde, à conceptualização do sistema escolar português como uma totalidade. A importância das iniciativas reformadoras de 1918 residiu em três pontos capitais: foi nomeado um numeroso conjunto de comissões encarregadas de estudar, em sentido amplo, as medidas de reforma necessárias em todos os ensinos e ainda em outras áreas consideradas afins, tendo como referencial um guião genérico comum. Em segundo lugar, a composição dessas comissões agregava, se não a totalidade, pelo menos uma seleção muito representativa das figuras intelectuais, científicas e culturais da época.

A importância coletiva da nomeação destas comissões e do seu funcionamento é reforçada por um terceiro aspeto, relacionado com a intenção explícita, formalizada, de coordenação e articulação de todos os estudos e propostas setoriais, através da constituição de uma Comissão Central com essa finalidade. Seria legítimo considerar que a dinâmica gerada no âmbito do trabalho das referidas comissões teria concorrido igualmente para reunir as condições que prepararam caminho, quer para a reforma de 1919 quer, 5 anos mais tarde, para a apresentação da proposta de Lei Camoesas, em 1923.

A listagem das portarias de 21 de janeiro de 1918 é esclarecedora quanto à abrangência do âmbito da intervenção de cada comissão de reforma. A primeira das portarias nomeia as comissões e estabelece a respetiva missão. São 11 as comissões nomeadas: I) de ensino universitário; II) de ensino secundário 
masculino; III) de ensino secundário feminino); IV) de ensino primário e normal; V) de ensino técnico; VI) de ensino agrícola; VII) de ensino artístico; VIII) de ensino dentário; IX) de bibliotecas e arquivos; X) de sanidade escolar; XI) de educação popular.

As comissões reuniam as figuras mais relevantes em cada área. Darei aqui maior destaque ao domínio do ensino primário e normal bem como da saúde escolar. Evidencio, por essa razão, os nomes de Fernando Alfredo Palyart Pinto Ferreira (professor do Instituto Médico-Pedagógico da Casa Pia de Lisboa e chefe da Repartição de Instrução Primária e Normal - comissão de ensino primário e normal); Ricardo Rosa y Alberty (professor primário e oficial comissão de ensino primário e normal); Sebastião Cabral da Costa Sacadura (médico e Inspetor Geral da Sanidade Escolar - presidente da comissão de sanidade escolar); António Aurélio da Costa Ferreira (médico e professor de pedologia da Escola Normal de Lisboa - comissão de sanidade escolar); Francisco Adolfo Coelho (professor da Faculdade de Letras de Lisboa presidente da comissão de educação popular e António Sérgio de Sousa (publicista - secretário da comissão de educação popular), entre outros.

Em 1919, o ensino primário é, mais uma vez, reorganizado e regulamentado pelas leis 5787-A e 5787-B, de 10 de maio de 1919, pelo decreto 6137, de 29 de setembro de 1919, retificado e alterado no Diário do Governo de 11 de dezembro de 1919. Os programas foram aprovados pelo decreto 6203, de 7 de novembro de 1919. A grande novidade foi a extensão da escolaridade obrigatória do primário geral a cinco anos, para todas as crianças compreendidas entre os sete e os doze anos.

A Reforma de 1919, ou melhor, as Reformas, apresentam algumas características notáveis. $\mathrm{O}$ aspeto mais relevante reside na estreita ligação existente entre os conteúdos dos programas do ensino primário geral, do ensino primário superior e do ensino normal primário. Outro aspecto decisivo é o que remete para a relação direta pretendida entre a formação inicial dos professores e os programas. 
Adolfo Lima considerava que tinha sido a partir da organização curricular de 1919, que emergira um cunho verdadeiramente profissionalizante no ensino proporcionado pelas escolas normais primárias. Até essa data, aquelas instituições não teriam passado de "meros estabelecimentos de instrução de ensino geral, com o intuito de dar conhecimentos e não métodos acerca das diversas disciplinas da educação primária” que a disciplina de Pedagogia apenas aflorava (LIMA, 1927, p. 20). A metodologia ganhou destaque nos programas normais primários, em 1919, inserida numa aposta no caráter necessariamente prático e aplicado da formação profissional do professor.

\footnotetext{
Na escola normal faz-se ciência, sim, mas ciência aplicada, - a ciência dos métodos pedagógicos. Por consequência, a Metodologia, sendo o eixo do ensino normalista, deve ser essencialmente prática, criadora do saber sistematicamente metodizado, para depois esse saber ser comunicado e ensinado também sistematicamente metodizado Decreto $\mathrm{n}^{\circ}$ 6203, de 7 de novembro de 1919, Programas do Curso Normal - Metodologia, Instruções Pedagógicas.
}

A Pedagogia5 continuava a representar o saber que sustentava a prática. Agregava a si as várias disciplinas que configuravam o núcleo principal da formação pedagógico/didática, das quais importa destacar a História da Instrução Popular em Portugal e Legislação Comparada do Ensino Primário. O Decreto de 1919 afirma que "numa escola normal, numa escola essencialmente profissional, criadora de professores, a disciplina «Pedagogia» é o fundamento da educação que nela se deve ter como objetivo" 6 . Até, pelo menos, à década de 1920, a definição de Didática reporta-se à organização técnica, decorrente do enquadramento nos grandes princípios pedagógicos, dos métodos e processos de ensino.

Finalmente, do conjunto dos três momentos de Reforma que considerei estruturantes na conjugação de discursos de diversas proveniências no discurso

\footnotetext{
5 Na realidade, a disciplina intitulava-se Pedagogia e História da Educação.

${ }^{6}$ Decreto $\mathrm{n}^{0}$ 6203, de 7 de novembro de 1919, Programas do Curso Normal - Pedagogia Geral e História da Educação, Instruções Pedagógicas.
} 
pedagógico, com proeminência do discurso médico, cabe agora considerar a Reforma de 1923, data em que foi publicada no Diário do Governo, de 2 de julho. Embora nunca tenha passado de proposta de lei, a Reforma Camoesas assumiu uma enorme relevância, não apenas pelo que representou em si mesma, dos pontos de vista político e pedagógico, mas pelo que nos conduz ao entendimento mais amplo da construção social da escolaridade elementar de massas e do pensamento pedagógico, do final do século XIX às três décadas iniciais do XX. Na elaboração do Projeto, participaram figuras importantes do movimento pedagógico, nomeadamente, ligadas à Escola Nova, como Faria de Vasconcelos, que já tinha tido intervenção relevante na reforma de 1918.

António Nóvoa sublinhou que foi a primeira vez que, em Portugal, se formalizou num texto legislativo o desenho do Sistema Educativo, num conjunto articulado desde o jardim-de-infância à Universidade (NÓVOA, 1987, p. 547-548). No Projeto de Reforma, passaram a estar contempladas as escolas para "anormais", inclusão justificada pelo legislador a partir do aumento da percentagem de "anormais" ditadas pelas condições da vida social da época, e também passou a estar abrangido o amplo leque de escolas do ensino técnico, como as escolas agrícolas, comerciais, coloniais, domésticas, industriais e profissionais com o intuito de contribuir para a formação da literacia básica "de soldados qualificados do exército social do trabalho" (REFORMA DA EDUCAÇÃO, 1923, p.7-9).

Existe ainda outra razão para destacar a importância do Projeto de Reforma Educativa de 1923. Essa razão reside na própria figura do respectivo proponente, o ministro João Camoesas. Se o Projeto mobilizou a colaboração de algumas das figuras mais proeminentes do movimento pedagógico português, em sintonia com o que ocorria no movimento internacional, João Camoesas constitui um paradigma das dimensões interventivas na sociedade que caracterizam inúmeros protagonistas do discurso social e educativo da época. Essas características são essenciais para compreender os processos constitutivos do discurso pedagógico contemporâneo. 
Os traços biográficos de João Camoesas ilustram as dinâmicas de intervenção cívica, social e profissional dos médicos neste período, assim como os caminhos que levam à incorporação dos seus contributos no discurso pedagógico desta época, em Portugal. Tomo aqui como referência principal a sua biografia, da autoria de Filomena Bandeira, inserida no Dicionário dos Educadores Portugueses (NÓVOA, 2003, p. 237-241). Ele movimentou-se nos meios maçonicos e militou na política republicana, antes e depois da implantação da República. Foi deputado pelo Partido Democrático e Ministro da Instrução, em 1923 e 1925. Médico de formação, deslocou-se, enquanto médico escolar, aos Estados Unidos, em comissão de serviço, para lá estudar os serviços médicos escolares. Colaborou em diversos periódicos, como a Seara Nova e a Educação Social, com artigos sobre medicina social, taylorismo e organização científica do trabalho. Foi responsável pela secção de Fisiologia no Instituto de Orientação Profissional, dirigido por Faria de Vasconcelos, a partir de 1925 e publicou, em 1927, a sua tese de doutoramento O trabalho humano, onde abordava a temática do taylorismo e da organização científica do trabalho.

A Organização Científica do Trabalho, proposta por F. W. Taylor, teve uma repercussão relevante no pensamento pedagógico internacional da época, ilustrado pela apologia da sua aplicação à educação escolar, feita, entre outros, por Edouard Claparède ou Ovide Decroly. O modelo da organização científica do trabalho, proposto por F. W. Taylor teve ampla circulação em Portugal. A Revista Atlântida publicou, por exemplo, entre 1917 e 1918, um trabalho de Fernando de Vasconcelos, intitulado "A rotina e o trabalho cientificamente organizado - o taylorismo" ( $\mathrm{n}^{\mathrm{0}} 26$, p. 308-324; $\mathrm{n}^{\mathrm{o}} 27$, p. 397-406 e $\mathrm{n}^{0} 28$, p. 450-462); A Revista Escolar inseriu o artigo de A. Gilet "O taylorismo aplicado às escolas" no seu no 5 , em 1925 (p. 208-210). Os manuais de Pedagogia para professores incluíam referências ao contributo do taylorismo para a Pedagogia e também para a Orientação Profissional (PIMENTEL FILHO, 1919; LIMA, 1929, 1936).

A participação em organizações e eventos internacionais foi igualmente 
crucial. Adolfo Lima mencionava a participação portuguesa na Liga Internacional Pró-Educação Racional da Infância, fundada por Francisco Ferrer, por volta de 1906 da qual existia uma secção portuguesa, em Lisboa (LIMA, 1929, p.162-164). Referia também a Liga Internacional Pró-Educação Nova, criada em 1921, e a Associação Internacional para os Filmes Cinematográficos aderente àquela Liga, e da qual era representante, por Portugal, Álvaro Viana de Lemos. Indicava como órgão do movimento, em Portugal, a revista Educação Social, da qual era diretor, e dava destaque a uma secção especial dirigida por António Sérgio (LIMA, 1929, p. 187-203).

O desenvolvimento de uma imprensa periódica própria, de organizações docentes, de associações profissionais afirmavam sua identidade social através de um posicionamento face à Escola. Veja-se a Sociedade de Ciências Médicas, a Sociedade de Estudos Pedagógicos, A Liga de Instrução Nacional (CARVALHO; FERNANDES, 2004), a expansão de eventos como as Conferências Pedagógicas, os Congressos e as Exposições Mundiais, criaram uma rede onde confluíram práticas discursivas, saberes e textualidades através dos quais se desenhou a realidade percebida da Escola.

A profissionalização da atividade docente, na qual se inscrevia a importância da implementação das Escolas Normais, ocupou um lugar central nas preocupações e nas medidas tomadas pelos governos na viragem do século XIX para o XX. Não se tratou de, apenas, como durante muito tempo aconteceu, assegurar a transmissão dos saberes elementares que os futuros professores teriam que transmitir aos seus alunos, ou seja, da instrução. Tratava-se de educar, isto é, de socializar, recriando um mundo de vivências simbólicas. A resolução das características educativas da socialização das crianças fez-se acompanhar pela socialização de quem as ensinava, os seus professores, e pela interiorização da correspondência das características da organização e dos saberes escolares com as leis naturais do desenvolvimento das crianças e dos jovens.

À afirmação, cedo avançada no século XIX, acerca da incompetência das 
famílias para instruir as suas crianças, tinha-se juntado outra, a partir dos finais do século XIX e dealbar do século XX, mais subtil e sofisticada, a da insuficiência técnica e científica dos professores para assegurar uma educação adequada às características fisiológicas e mentais das crianças e dos jovens e ainda para corrigir as patologias geradas pela própria escola (WAGNON, 2013, p.87). O processo formativo dos espíritos era entendido como mais importante que as matérias objeto de ensino. O professor deveria ser esclarecido pelos verdadeiros especialistas, os médicos, os que conheciam a criança na sua especificidade intrínseca e nos seus fundamentos naturais.

\section{QUE DISCURSO PEDAGÓgICO PARA QUE ESCOLA HOJE?}

Cronologicamente situado num período de emergência das Ciências da Educação, nas primeiras décadas do século XX, procurei ilustrar no presente texto as interdependências e incorporações no discurso pedagógico de enunciados produzidos em contextos sociais e profissionais diversos pelos mesmos atores, os médicos. Diversos, porém, ligados pela intervenção social e política contemporânea desenhada a partir de estratégias de afirmação de identidades profissionais e de conquista da legitimação pelo Estado. Tratou-se de recordar alguns elementos relativos aos processos de profissionalização dos professores primários e dos médicos.

O contributo dos médicos foi decisivo na construção do discurso pedagógico que acompanhou o aperfeiçoamento e consolidação do modelo de escola graduada, em Portugal, entre os anos 1890 e 1930. Argumentei que o discurso médico, através da reivindicação da sua cientificidade acerca da criança, dos processos de aprendizagem e do ato pedagógico, contribuiu decisivamente para a naturalização do modelo da escola graduada vigente, ocultando a sua natureza socialmente construída. Sem se entender plenamente o seu caráter localizado histórica e socialmente, a alteração do modelo da Escola 
atual está comprometida e votada ao fracasso porque não supera a racionalidade institucionalizada no saber comum do ato pedagógico e regressa, por inércia, aos pressupostos de cientificidade com que foi erigida. Com esta problematização, pretendi demonstrar a importância do mapeamento sistemático dos conteúdos que deram substância a essa cientificidade socialmente construída e contribuir para uma renovação das possibilidades de reinvenção da organização da Escola, através do debate em torno de novos pressupostos científicos que a sustentem.

\section{REFERÊNCIAS}

BANDEIRA, Filomena. João José da Conceição Camoesas. [António NÓVOA, dir.] Dicionário de Educadores Portugueses, Porto: Asa, p. 237-241, 2003.

BERNSTEIN, Basil. On pedagogic discourse. [John Richardson, ed.]

Handbook of theory and research for the sociology of education. New York, Westport Conn. \& London: Greenwood Press, p. 205-240, 1986.

BERNSTEIN, Basil. The structuring of pedagogic discourse. Volume IV: class, codes and control. London \& New York: Routledge, 1990.

CARVALHO, Luís Miguel; FERNANDES, Ana Lúcia. Mens agitat molem: The Pedagogical Congresses of the Liga Nacional de Instrução (Lisbon, 1908-1914), Paedagogica Historica, 40:5-6, 685-703, 2004.

CONRAD, Peter. Medicalization and Social Control. Annual Review of Sociology, vol.18, p. 209-232, 1992.

CORREIA, António Carlos Luz; SILVA, Vivian Batista da Silva. Manuais pedagógicos - Portugal e Brasil - 1930 a 1971 - Produção e circulação internacional de saberes pedagógicos. Cadernos Prestige, 13. Lisboa: Educa, 2002

CORREIA; António Carlos Luz; PERES, Eliane T. Aprender a ser profesor a través de los libros: Representación profesional, currículum escolar y modelos de aprendizaje en los manuales de pedagogía y didáctica para la formación de profesores de enseñanza primaria en Portugal (1870-1950), in [GUEREÑA, J.L.; OSSENBACH, Gabriela y Pozo, M., dir.], Manuales escolares en 
España, Portugal y América Latina (siglos XIX y XX). Madrid: Uned, p. 195-213, 2005.

CORREIA, António Carlos da Luz. O tempo e as temporalidades da escola em Portugal (Séculos XVIII-XX). Porto: Estratégias Criativas, 2019.

CORREIA, António Carlos da Luz. Sebastião Cabral da Costa Sacadura. [António NÓVOA, dir.] Dicionário de Educadores Portugueses, Porto: Asa, p.1231-1234, 2003.

COSTA, Jaime Celestino da. A. Celestino da Costa e a sua Época. Separata do Jornal da Sociedade das Ciências Médicas de Lisboa, Tomo CXLIX, junho, nº 6. Lisboa: Sociedade das Ciências Médicas de Lisboa, p. 368 a 375, 1985 .

COSTA, Jaime Celestino da. A geração médica de 1911: origem, realização e destino. Lisboa: Faculdade de Medicina, 2000.

DORIA, José Luís. O XV Congresso Internacional de Medicina in [VELOSO, A. J. coord. ] Médicos e Sociedade. Para uma História da Medicina em Portugal no século XX. Lisboa: By The Book, 2a ed., p. 79-96, 2017.

FERREIRA, António Aurélio da Costa. O ensino dos anormais. De como ele aproveita indivíduos julgados inúteis e do que no género se está fazendo entre nós com resultado. Anuário da Casa Pia de Lisboa. Ano económico de 1913-1914, Lisboa: Tipografia Casa Portuguesa, p.181-187, 1914.

FERREIRA, António Aurélio da Costa. Algumas lições de Psicologia e Pedologia. Lisboa: Lumen, 1921.

FERREIRA, António Gomes. A criança e a pedologia no contexto da Primeira República em Portugal in [MOURÃO, Alda; GOMES, Ângela Castro coord. ] A experiência da Primeira República no Brasil e em Portugal. Coimbra: Imprensa da Universidade de Coimbra, p. 299-316, 2014.

FERREIRA, António Gomes. Higiene e controlo médico da infância e da escola. Cadernos CEDES, v. 23, n. 59, p. 9-24, abril 2003.

FOUCAULT, Michel. The birth of social medicine In Power, Essential works of Foucault 1954-1984, vol.3. London: Penguin, p. 134-156, 2002.

GARNEL, Maria Rita Lino. O poder intelectual dos médicos. Revista da História das Ideias. Vol. 24, p.213-253, 2003

JODELET, Denise. Les représentations sociales. Paris : Presses

Universitaires de France, $7^{\mathrm{a}}$ edição, 2003. 
LIMA, Adolfo. Metodologia: lições de metodologia professadas na escola normal primária de Lisboa. Lisboa: Livraria Férin, I vol., $2^{\mathrm{a}}$ ed., 1927.

LIMA, Adolfo. Metodologia: lições de metodologia professadas na escola normal primária de Lisboa. II vol. Lisboa: Livraria Férin, 1932.

LIMA, Adolfo. Pedagogia sociológica. $1^{\circ}$ vol. Lisboa: Couto Martins, 1929.

LIMA, Adolfo. Pedagogia sociológica: princípios de pedagogia e plano de organização geral de educação. $2^{\circ}$ volume. Porto: Livraria Escolar Progredior, 1936.

MOSCOVICI, Serge. Representações sociais: investigações em psicologia social. Petrópolis, Editora Vozes, $2^{\mathrm{a}}$ edição, 2004.

NÓVOA, António. Le temps des professeurs. Lisboa: INIC, 2 vols., 1987.

NÓVOA, António, dir. A imprensa de educação e ensino: repertório analítico (séculos XIX-XX). Lisboa, Instituto de Inovação Educacional, 1993.

NÓVOA, António dir. Dicionário de educadores portugueses. Porto, Edições Asa, 2003.

NÓVOA, António. Professionalisation des enseignants et sciences de

l'éducation. Paedagogica Historica, 34, sup.1, p.403-430, 1998.

PIMENTEL FILHO, Alberto. Lições de pedagogia geral e de história da educação. Lisboa, Guimarães \& $C^{\mathrm{a}}, 1919$.

PIMENTEL FILHO, Alberto. Lições de pedagogia geral e de história da educação. Lisboa: Guimarães \& C. a , ${ }^{\text {a }}$ ed. Melhorada, 1935a.

PIMENTEL FILHO, Alberto. Pedologia: esboço de uma história natural da criança. Lisboa: Guimarães \& C. a , 1929.

PIMENTEL FILHO, Alberto. Pedologia: esboço de uma história natural da criança. Lisboa, $2^{a}$ ed., 1935 b.

PIMENTEL FILHO, Alberto. Psico-fisiologia: resumo das lições professadas na escola normal de Lisboa no ano lectivo de 1915-1916. Lisboa: Guimarães \& C. ${ }^{\mathrm{a}}, 1916$.

PIMENTEL FILHO, Alberto. Súmula didáctica. Lisboa, Livraria Editora Guimarães \& Ca 1934 .

PINELL, Patrice. L’invention de l'échelle métrique de l'intelligence. Actes de la Recherche en Sciences Sociales, 108, juin, p. 19-35, 1995. 
PINELL, Patrice. The Genesis of the Medical Field: France, 1795-1870. Revue française de sociologie, 52, Supplement, 2011, p.117-15.1

PORTER, Dorothy; PORTER, Roy. What Was Social Medicine? An Historiographical Essay. Journal of Historical Sociology, vol.1, $\mathrm{n}^{0} 1$, March, p. 90-106, 1988.

Reforma da Instrucção primária decretada em 24 de dezembro de 1901 seguida dos modelos d'instrucções ao governo. Porto: Livraria Portuense de Lopes \& $\mathrm{C}^{\mathrm{a}}, 1902$.

REFORMA DA EDUCAÇÃO: proposta de lei. Diário do Governo. Separata de 2 de julho. Lisboa: Imprensa Nacional, 1923.

SACADURA, Sebastião da Costa. Protecção à primeira infância - Excerpto do trabalho lido na Associação Protectora da Primeira Infância, separata da Medicina Contemporânea, $\mathrm{n}^{0} 53,31$ de dezembro. Lisboa: Typographia Adolpho de Mendonça, p. 4 e 5, 1911.

SILVA, Vivian Batista da. Saberes em viagem nos manuais pedagógicos: construções da escola Portugal e no Brasil (1870-1970). São Paulo: Editora UNESP, 2018.

VARELA, Julia. Categorías espacio-temporales y socialización escolar: del individualismo al narcisismo. Revista de Educación, Tiempo y espacio, 298, p. 7-29, 1992.

VARELA, Julia; ALVAREZ-URIA, Fernando. Arqueología de la escuela. Madrid: Las Ediciones de La Piqueta, 1991.

VASCONCELOS, Faria de. Lições de pedologia e pedagogia experimental. Lisboa: Antiga Casa Bertrand / José Bastos \& Cia,1909.

VASCONCELOS, Faria de. Lições de Pedologia e Pedagogia Experimental. Paris-Lisboa: Livrarias Aillaud e Bertrand, $2^{\mathrm{a}}$ ed. 1923

VELOSO, A. J. Barros, coord. Médicos e Sociedade. Para uma História da Medicina em Portugal no século XX. Lisboa: By The Book, $2^{\mathrm{a}}$ ed., 2017a.

VELOSO, A. J. Barros. A era das especialidades (1900-1980). [VELOSO, A. J. Barros, coord. ] Médicos e Sociedade. Para uma História da Medicina em Portugal no século XX. Lisboa: By The Book, $2^{a}$ ed., p. 439-459, 2017.

WAGNON, Sylvain. Ovide Decroly, un pédagogue de l'Éducation nouvelle 1871-1932. Bruxelles: P.I.E. Peter Lang, 2013. 
ANTONIO CARLOS CORREIA é professor auxiliar convidado do Instituto de Educação da Universidade de Lisboa.

E-mail: correiaantonio57@gmail.com

(i) http://orcid.org/0000-0002-4090-4552

Recebido em: 27 de maio de 2019

Aprovado em: 30 de setembro de 2019

Revista História da Educação - RHE

Associação Sul-Rio-Grandense de Pesquisadores em História da Educação - Asph

Artigo de acesso aberto distribuído nos termos de licença Creative Commons. 